\title{
3 Research Square

\section{Remote Learning and Teaching in Southern Africa: A Case Study of Health Professions Education Institutions}

Shalote Chipamaunga ( $\nabla$ src@pcbillc.com )

University of Zimbabwe

Champion Nestai Nyoni

University of the Free State

Mike Nantamu Kagawa

Makerere University

Quenton Wessels

University of Namibia

Elliot Kafumukache

University of Zambia

\section{Rudo Gwini}

National University of Science and Technology

Gwendoline Kandawasvika

University of Zimbabwe

Patricia Katowa-Mukwato

University of Zambia

Rangarirai Masanganise

University of Zimbabwe

Rudo Nyamakura

University of Zimbabwe

Idah Nyawata

University of Zimbabwe

Louise Pretorius

University of Namibia

Kefalotse Dithole

University of Botswana

Clemence Marimo

Cavendish University Zambia

Aloysius Gonzaga Mubuuke

Makerere University

Scovia Nalugo Mbalinda 
Makerere University

Lynette Jean van der Merwe

University of the Free State

Detlef Prozesky

University of Botswana

\section{Research Article}

Keywords: ADKAR framework, COVID-19, ERT, FOL, health professions education, remote learning and teaching, Southern Africa, undergraduate programme

Posted Date: October 8th, 2021

DOI: https://doi.org/10.21203/rs.3.rs-922783/v1

License: (c) (i) This work is licensed under a Creative Commons Attribution 4.0 International License. Read Full License 


\section{Abstract \\ Background}

Southern Africa, like other parts of the world, has always strived to deliver quality health professions education. These efforts have been influenced to a larger extent by the socio-economic and cultural context of the region, but also by what happens globally. The global disruption caused by the COVID-19 pandemic necessitated the implementation of emergency remote teaching (ERT) to continue delivering on the mandate of educating future health professionals in 2020. The purpose of this research was to describe the change process through which selected health professions education institutions (HPEls) in the Southern African region adjusted their academic programmes for remote learning and teaching during the COVID-19 related pandemic.

\section{Methods}

A mixed methods study with a case study design was applied using the ADKAR model as a conceptual framework for data interpretation. The study population consisted of educators, students, and administrators in undergraduate medical and nursing programmes from six institutions in five countries.

\section{Results}

A total of 1,307 respondents provided data for the study. Many of the institutions were caught off-guard when most educators and almost all students were required to leave their universities and go into isolation at home. Stakeholders immediately became aware of the need to adopt online approaches as an emergency measure. In all programmes, educators, students, and administrators agreed that they should change and wanted to change, and some students realised that they had to take charge of their own learning independently. Overall educators reported confidence with the use of standard Microsoft software, while knowledge of learning management systems proved more challenging for both educators and students. Many stakeholders, especially students and administrators, reported uncertainty about their ability to function in the new reality. Conducive family dynamics, a quiet space to study, good connectivity, a reliable electricity supply and appropriate devices were reported to reinforce learning and teaching.

\section{Conclusions}

The findings highlight the need to scale up educational infrastructure, prioritise strategic directives, drive continuous professional development of educators and foster co-constructivist approaches towards student centered education, including formal online learning. 


\section{Background}

The outbreak of Coronavirus disease 19 (COVID-19) infection became a global pandemic in March 2020 and caused widespread disruption in all spheres of society. Countries had to adopt containment and mitigation measures such as restrictions on the movement of persons and human congregation $[1,2]$. Planned educational events requiring physical interactions were suspended or cancelled, especially in higher education institutions in Africa, many of which were indefinitely closed [3]. The restrictions related to COVID-19 were so rapid that contingency measures for continued learning and teaching activities could not be adequately planned. Students and educators were physically isolated and disconnected from mainstream educational settings, where face-to-face instruction was the dominant approach to learning and teaching, especially in the health sciences disciplines [3]. Health professions education institutions in Southern Africa were greatly affected by these measures [4]. Both educators and learners had to find ways of remaining connected and to ensure that some form of learning continued.

Social, economic, and cultural contexts influence health professions education programmes and their adaptation to crisis situations such as the COVID-19 pandemic worldwide - so too in Southern Africa. Health professions education in Southern Africa is predominantly offered in residential universities and colleges using pedagogical approaches which integrate face-to-face and blended classroom teaching and clinical placements [5]. Medical and nursing programmes are strongly influenced by the capacity of institutions and the contextual need to produce human resources for health to achieve universal health coverage [5]. The majority of the countries in this region are classified as low-income countries with insufficient investment in health and health professions education [5]; this lack of training resources explains the limitations experienced in developing comprehensive contingency strategies to cope with disruptions in education processes. Clinical education relies on authentic clinical learning within hospitals and clinics, supplemented by simulation-based education and other innovative pedagogies [6, 7]. The disruptions caused by COVID-19 arguably affected the attainment of competence among students in the health professions in this region [8].

Some health professions educational institutions (HPEls) in Southern Africa reported adopting emergency remote teaching (ERT) as a strategy for educators to continue engaging with their students during the COVID-19 pandemic [5]. ERT is described as a short-term solution aimed at achieving temporary access to instruction, in a manner that is quick to set up and is reliable during crises which disrupt formally planned educational activities [6]. Several authors present compelling evidence that ERT can be a precursor for formal online learning (FOL), which has long been recommended as a strategy for health professions education [9-11]. While suggestions for FOL have taken on an increased impetus, they are not new: the World Health Organization (WHO), in its publication in 2013 on "Transforming and Scaling up Health Professionals' Education and Training" recommended FOL as a tool for interprofessional education, mainly if it is delivered in an open-access environment[10]. With the advent of the Fourth Industrial Revolution, institutions which had not taken serious measures to migrate to a higher level of technology use would have been aware that they were lagging behind with requirements of modern educational approaches. The COVID-19 pandemic clearly exposed the limited uptake of this 
recommendation from WHO in the Southern African region - hence ERT being used as a proximal alternatives $[12,13]$.

Since the onset of the COVID-19 pandemic, literature on the adoption of ERT in health professions educational programmes has been emerging rapidly $[14,15]$. Institutions are documenting essential experiences and lessons which are further incorporated into sustainable formal online strategies. However, most of this literature is from developed countries whose recommendations may not be useful within the health professions education context of the Southern African region [12]. There is limited published literature regarding the experiences of ERT from less-resourced settings, such as those from institutions in the Southern African region $[16,17]$. We suggest that a description of the awareness, desire, knowledge and ability of stakeholders from these institutions about adopting ERT, as well as factors reinforcing such adoption, is important in winnowing strategies that could be adopted to formalise FOL in the region. In future, HPEls in developing countries are bound to face similar challenges to those outlined in this publication. The purpose of this research was therefore to describe the preparedness of selected HPEls in the Southern African region regarding ERT and the potential for FOL.

\section{Methods}

In this study we used the ADKAR framework [18-20] to formulate the research questions, and analyse and interpret data (Fig. 1). This framework focuses on stakeholders' Awareness of the need for change; their Desire to participate in and support the change; whether they have the Knowledge needed for the change and the Ability to implement required behaviours; and the Reinforcement they need to sustain the change. The stakeholders were educators, administrators and students in the programmes and the study questions refer to them.

\section{Study questions}

1. Were stakeholders aware of the need to adjust to remote learning and teaching?

2. Did stakeholders desire to participate in and support remote learning and teaching?

3. What knowledge and skills did stakeholders have to carry out remote learning and teaching?

4. What abilities did stakeholders require to carry out remote learning and teaching?

5. What factors did stakeholders perceive to reinforce and sustain or obstruct remote learning and teaching?

\section{Research design}

A mixed methods approach with a case study design was applied in this study [21]. The case study design allowed the researchers to explore in-depth the complex issues regarding the change process surrounding ERT in the real-life setting of the participating institutions in Southern Africa. It also allowed 
the researchers to acknowledge the various contextual influences in health professions education programmes across the region, appreciating each case as it exists. In Yin's classification a Type 4 case study design was used which includes multiple units of analysis with multiple cases [22].

\section{Study populations and sampling}

The study population consisted of educators, students and administrators in undergraduate medical and nursing programmes from the following institutions: the National University of Science and Technology (Zimbabwe), University of Botswana, University of the Free State (South Africa), University of Namibia, University of Zambia, and University of Zimbabwe. These institutions were purposively selected over a period of two months on the basis of their willingness to participate in the study and share their experiences on their response to the COVID-19 pandemic [23]. Within this group, homogeneous sampling was applied by inviting those with nursing and medical programmes to participate. Deans, Heads of Departments and administrators responsible for information, communication and technology (ICT) services were identified as administrators; since teaching and administrative functions may overlap, individuals were allocated to a category based on the main focus of their work. Whole populations of each group in each programme were sampled for the study. This was done since the quantitative data which were also collected for the case studies would provide an opportunity for specific comparisons between programmes. All included participants had to be engaged in or have experience related to ERT in their programme or institution.

\section{Data collection}

In each institution data collection commenced immediately after ethics clearance was obtained locally (Table 1).

Table 1

Institutions review board (IRB) numbers

\begin{tabular}{|ll|}
\hline Institution & IRB numbers \\
\hline University of Zimbabwe & JREC/143/2020 \\
\hline University of the Free State & UFSHSD2020/1813 \\
\hline University of Zambia & NHRA approval letter with no reference number \\
\hline University of Namibia & H-G/589/2020 \\
\hline National University of Science and Technology & FMNUST03/07/202 \\
\hline University of Botswana & UBR/RES/IRB/BIO/GRAD/219 \\
\hline
\end{tabular}

Data were collected starting on October 1st, 2020 and ending on March 31st, 2021. Quantitative and qualitative data were collected using researcher developed questionnaires with structured and semistructured elements. Separate questionnaires were designed for educators, students and administrators. 
The questionnaires focused on information regarding the programme, the educational situation before COVID-19 and the institutional response to the COVID-19 pandemic. The ADKAR model determined the structure of questions related to the institutions' response to the COVID-19 pandemic. Piloting of the questionnaire was carried out using two volunteers from each stakeholder group across all institutions included in this study and adjustments were made to the questionnaires based on the pilot outcomes. Potential participants were invited to the study at institution level through an electronic information leaflet which explained the purpose and process of engaging with the study. An option to opt out of the study was presented and implied consent was assumed when participants proceeded to complete the questionnaire. Questionnaires were prepared for online completion and submission; however, in some cases where access to the electronic link to the questionnaire was not feasible, anonymised paper versions of the questionnaire were distributed and data were entered on behalf of the participants into the electronic platform.

\section{Data analysis}

Data were analysed through a multi-step deductive process aligned with the ADKAR framework.

1. Researchers in each programme first analysed their data to produce a case study:

- The initial step applied descriptive statistics which captured the frequencies of quantitative responses from the structured questions.

- The next step consisted of open coding to create categories to groups and summaries of the qualitative data. These data provided additional depth to the quantitative data.

- Third summarised qualitative and quantitative data were integrated using the framework shown in Table 2 below, and through triangulation, themes were produced for each element of the ADKAR model for each programme. The summarised data were presented as a complete case study.

2. The final step of analysis amalgamated the cases from each programme and institutions across the entire region under the elements of the ADKAR model of change, again using the framework shown in Table 2. In this way a collective case study was developed integrating all the individual cases.

Due to the variations in response rates across the data collection sites, our original intention to use quantitative data for cumulative inferences aimed at generalization across the Southern African region could not be realised. 


\section{The nature of the programmes}

\subsection{Medical/ Nursing}

\subsection{Number of staff, students, and administrators in the programme}

2. Baseline situation

2.1. How teaching was done before the lockdown

3. Awareness of the need for change

3.1. How National and University policy brought about an awareness on the part of stakeholders that they had to change the way they work

4. Desire to participate in change

4.1. How stakeholders decided to play their part in managing the new reality

4.2. How learning, teaching, and support actually changed

5. Knowledge and skills needed

5.1. Stakeholders' knowledge about and experience in using tools they had to use to manage the new reality

6. Ability to implement change

6.1. The self-perceived ability of stakeholders to manage the new reality

7. Reinforcement to sustain change

7.1. Resources available to stakeholders to work in the new reality

7.2. Factors supporting and sustaining the change to working in the new reality

7.3. Factors hindering the change to working in the new reality

\section{Ethical approval and consent to participate}

For each institution ethical clearance was obtained from its own institutional review board or committee, having provided the information required in each situation. The principles of the Belmont report of 1979 and the International Conference on Harmonization (ICH) of 2002 were applied to safeguard the participants $[24,25]$. All participants received information related to the study and participation was voluntary. Anonymity and confidentiality were maintained throughout this study.

\section{Trustworthiness}

Elements of trustworthiness were applied in this study [24]. We attempted to enhance the credibility of our research by triangulating qualitative and quantitative data within each programme, and triangulating the themes obtained between stakeholders. We also communicated regularly between ourselves to 
standardise data collection and analysis. Our decision to involve several programmes in the research should enhance the transferability of the findings to other health professions education programmes in different contexts. We paid attention to the dependability of the research by rigorously documenting our discussions and decisions in detailed minutes of our fortnightly meetings. Finally, we tried to ensure conformability by designing written guidelines to guide each step of the research process, thereby illustrating how we reached our conclusions.

\section{Results}

A total of 1,307 respondents provided data for the study from eleven progammes at six institutions in five countries (Tables 3 and 4).

Table 3

Programmes and countries

\begin{tabular}{|llll|}
\hline Country & \multicolumn{2}{l}{ Programmes } & Total \\
\cline { 2 - 3 } & Medical & Nursing & \\
\hline Botswana & 1 & 1 & 2 \\
\hline Namibia & 1 & 1 & 2 \\
\hline South Africa & 1 & 1 & 2 \\
\hline Zambia & 0 & 1 & 1 \\
\hline Zimbabwe & 2 & 2 & 4 \\
\hline TOTAL & & & 11 \\
\hline
\end{tabular}

Table 4

Respondents

\begin{tabular}{|lllll|}
\hline Programmes & Educators & Students & Administrators & Total Respondents \\
\hline Nursing & 102 & 518 & 28 & 1307 \\
\cline { 1 - 2 } Medical & 116 & 543 & & \\
\hline
\end{tabular}

The results in this section will first provide an overview of the pre-COVID-19 educational approach at each programme and institution, followed by the elements of the ADKAR model in sequence to reflect responses to the COVID-19 pandemic. The factors under each of the five elements which represent the milestones programmes should achieve for change to be successful build on each other and are interrelated.

\section{The pre-COVID-19 situation}


Most nursing programmes lasted four years and most medical programmes lasted five years. Curricular models varied across programmes, with the traditional model of preclinical teaching for two years followed by clinical teaching predominating. Learning and teaching were reported to take place face-toface, integrating laboratory and clinical work across all the institutions. Some institutions informally used blended learning approaches through established learning management systems; however most institutions did not use electronic platforms to enhance learning. All summative assessments were reported to be conducted face-to-face, including direct observation in the clinical environments. Administrators reported regular meetings with programme stakeholders to identify problems and offer support in solving them.

\section{The response to COVID-19}

The response to COVID-19 describes approaches used by the programmes and institutions in response to the pandemic and related restrictions from the viewpoint of educators, students, and administrators across the five institutions included in this study.

\section{Awareness}

Awareness of the need for change evolved as the pandemic unfolded. All three groups of stakeholders became immediately aware of major changes, when national regulations obliged most educators and almost all students to leave their universities and go into isolation at home. Some staff members were allowed to continue working from their offices but with strict measures to limit disease transmission. Over time these measures were relaxed piecemeal to varying degrees in different programmes, with students eventually being allowed to return to their universities under strict control measures:

"Staff members are expected to continue teaching as usual but with measures to prevent transmission (e.g., masking, social distancing, hand hygiene) strictly enforced” (Educator).

With lockdown, academic programmes were suddenly disrupted, and educators realised the need for remote teaching. Students realised that they had to do the best they could to continue learning at home, while waiting for guidance from their programme administrators. Administrators realised that they had to work online now, giving additional support to educators and students:

"We have been working under pressure covering a learning workload of 9 months in 3 months. We have been having ward rounds for reduced period when we open school for the reduced time and our weeks for ward round rotations have been halved. More than 80 percent of lectures have been delivered online" (Student).

The transition to online teaching did not occur immediately. For the first time educators were expected to work remotely, and this changed their approach to teaching. They became aware that they had to adopt online approaches and tried to use whatever method available or known to them to teach the subject content - including social media platforms (WhatsApp and Facebook), business communication platforms (Microsoft Teams and Zoom), learning management systems (Blackboard, Moodle and Google 
Classroom), and narrated lecture PowerPoint slides along with audio recordings of questions and answers. For many, this would be an adjustment with a steep learning curve, immediately and in future:

"COVID -19 has changed the Education Industry - A lot of new innovations will take place. Universities need more funding to support the students and staff to use this technology in the near future."

(Administrator)

"Online teaching is the way to go and should not be stopped even after the COVID-era". (Administrator).

Educators and students also became aware that pandemic-related restrictions would severely hamper clinical teaching. In addition, educators and students soon became aware of severe limitations that would be imposed by poor connectivity, especially in rural communities, the cost of internet packages, and unsuitable communication devices:

"After the initial hard lock down with students and staff at home, some students were allowed to return to university. However, the academic year was then markedly shortened and clinical rotations had to be condensed. Due to restrictions on clinical platforms, we had to move to more simulated and paper-based teaching rather than teaching in the wards and clinics with actual patients. The same applied for assessments" (Educator).

\section{Desire}

Desire to support change was assessed in terms of whether participants perceived they should support their programmes in the new reality, and the changes in practice that this desire brought about. In all programmes, educators, students, and administrators almost universally agreed that they should change and wanted to change:

"The desire to deliver some teaching to students drives me forward ..." (Educator)

"Apply personal effort to the best of my abilities.... Find alternative means in which I can successfully cover most the learning materials given the curriculum" (Student).

Educators wanted to change from face-to-face to online teaching which they also wanted to master. They would offer online teaching synchronously or asynchronously as circumstances demanded and only conduct face-to-face practical teaching when it could be done safely, supporting students with the resources they needed:

"The crisis became an opportunity for me to learn and sharpen my skills on online teaching. An opportunity to help support students that were resisting change and help them change their mindset and progressed well." (Educator).

Students made it clear that they wanted the educational changes to work for them so that their studies could succeed - rather passively in some cases, looking for guidance from educators, but in several instances realising that they had to take charge of their own learning independently. Administrators in 
some institutions wanted to provide increased support online to staff and students, to plan for increased ICT training and adequate connectivity and where possible to extend counselling services:

"I am available to staff members to discuss their needs and challenges" (Administrator)

Changes in practice resulting from a desire to change were broadly similar across programmes despite individual differences and strengths. Educators reported that their teaching changed completely or partly with the widespread use of relevant and available online platforms and software, and clinical teaching adapted for safety. Theory teaching became almost entirely remote with materials being provided online or by email. Theory assessment was also done online, using tools like open book exams, assignments, and participation in discussions. During strict lockdown, clinical and skills teaching was limited and focused on relevant theory using case studies and demonstration videos. Skills assessment had to be limited to their theory component, with some innovations like assessing student videos. Forced by circumstances individuals had to adapt, but there was a strong desire for face-to-face teaching and assessment to resume their proper place as circumstances permitted. Students similarly reported major changes in learning with online learning for theory predominating and student-led use of social media, search engines, and peer support.

"Treat online learning as I would face to face teaching and equip what's missing with e.g. You Tube learning videos" (Student)

Students, too, experienced reduced clinical and skills learning and assessment. Although there were some differences, the 'Desire to support change' was demonstrated to be remarkably similar among all programme stakeholders across all institutions.

\section{Knowledge}

According to the ADKAR model, knowledge on how to change is important for change to take place. Assessing existing knowledge is recommended because the size of the knowledge gap may impact the success of the adoption of the desired change. This study asked participants to rate themselves on their confidence in using software needed for ERT and their experience in tools needed for ERT (Tables 5, 6 and 7). 
Table 5

Reported educator and student confidence in using software needed for ERT

\begin{tabular}{|llll|}
\hline Tool & $\begin{array}{l}\text { Reported } \\
\text { confidence }\end{array}$ & $\begin{array}{l}\text { Educators \% } \\
\mathbf{( N = 2 1 8 )}\end{array}$ & $\begin{array}{l}\text { Students \% } \\
\mathbf{( N = 1 0 6 1 )}\end{array}$ \\
\hline Microsoft Word & Very confident & 91.2 & 66.5 \\
\cline { 2 - 4 } & Some confidence & 8.3 & 31.5 \\
\cline { 2 - 4 } Microsoft PowerPoint & Not at all & 0.5 & 2.0 \\
& Very confident & 91.2 & 59.7 \\
\cline { 2 - 4 } & Some confidence & 8.8 & 37.1 \\
\cline { 2 - 3 } $\begin{array}{l}\text { Search engines (e.g. Google, } \\
\text { Firefox) }\end{array}$ & Not at all & 0 & 3.2 \\
& Very confident & 79.7 & 72.7 \\
\cline { 2 - 4 } & Some confidence & 19.8 & 24.5 \\
\cline { 2 - 4 } & Not at all & 0.5 & 2.8 \\
\hline
\end{tabular}

Table 6

Reported educator and student experience of tools that support ERT

\begin{tabular}{|llll|}
\hline Tool & Reported use & Educators (N=218) & Students (N=1061) \\
\hline WhatsApp & Often & 32.9 & 37.0 \\
\cline { 2 - 4 } & Sometimes & 47.5 & 47.5 \\
\cline { 2 - 4 } Zoom, Skype, BlueJeans & Never & 19.6 & 15.5 \\
& Often & 40.8 & 41.7 \\
\cline { 2 - 4 } & Sometimes & 36.4 & 41.5 \\
\hline e-platforms (Moodle, Teams etc.) & Often & 55.0 & 16.7 \\
\cline { 2 - 4 } & Sover & 22.8 & 45.3 \\
\cline { 2 - 4 } & Sometimes & 26.5 & 24.2 \\
\cline { 2 - 4 } & Never & 18.5 & 30.4 \\
\cline { 2 - 4 } & &
\end{tabular}


Table 7

Reported administrator confidence in using tools which support ERT

\begin{tabular}{|lll|}
\hline Tool & Reported use & \% $(\mathbf{N}=\mathbf{2 7})$ \\
\hline Microsoft Office & Very confident & 55.6 \\
\cline { 2 - 3 } & Some confidence & 33.3 \\
\cline { 2 - 3 } Zoom, Skype, BlueJeans & Not at all & 11.1 \\
& Very confident & 33.3 \\
\cline { 2 - 3 } & Some confidence & 55.6 \\
\cline { 2 - 3 } e-platforms (Moodle, Teams etc.) & Not at all & 11.1 \\
\cline { 2 - 3 } & Very confident & 33.3 \\
\cline { 2 - 3 } & Some confidence & 63.0 \\
\cline { 2 - 3 } & Not at all & 3.7 \\
\cline { 2 - 2 } &
\end{tabular}

It was evident that respondents were aware of the knowledge and skills needed to implement ERT and learning as a potential impediment to remote learning and teaching:

"Lecturer incompetence with ZOOM" (Student).

Overall educators in all programmes reported high confidence levels with the use of commonly used tools like Microsoft Word, PowerPoint and e-mail; confidence with search engines was reported to be lower. Educators recognised WhatsApp as a useful tool for ERT but their experience with it was limited; so too for Zoom, Skype and Teams and common e-learning platforms. For all these tools a diverse skill range was reported between programmes.

"I have some knowledge of some of the teaching platforms and I should manage with some support from the University" (Educator).

Overall, students' reported confidence in using Microsoft programmes was lower than that of educators but their confidence in using search engines was the same (Tables 5 and 6). Students' reported experience of tools like WhatsApp and Zoom resembled that of their educators but many had no experience of platforms like Moodle and Teams. Administrators reported general competence in the tools they needed to support the programme.

\section{Ability}

Ability may be regarded as the transition from knowledge to action. Many factors that impact this process include resources, physical and intellectual capability, time and psychological blocks, and fears [20]. Stakeholders' ability to implement new skills and behaviours required for ERT was determined in several ways. Their confidence in the use of relevant software and platforms was assessed (Tables 5 and 
7) and revealed varying levels of ability. Stakeholders were also asked to report on their overall ability in relation to ERT (Table 8).

Table 8

Reported stakeholder ability to perform in ERT

\begin{tabular}{|llll|}
\hline & $\begin{array}{l}\text { Completely } \\
\%\end{array}$ & $\begin{array}{l}\text { Partially } \\
\%\end{array}$ & $\begin{array}{l}\text { Not at all } \\
\%\end{array}$ \\
\hline $\begin{array}{l}\text { Educators' reported ability to conduct teaching in ERT } \\
(\mathrm{N}=161)\end{array}$ & 48.4 & 45.3 & 6.2 \\
\hline $\begin{array}{l}\text { Students' reported ability to learn effectively in ERT } \\
(\mathrm{N}=947)\end{array}$ & 14 & 73.5 & 12.5 \\
\hline Administrators' reported ability to support ERT (N=23) & 13 & 87 & 0 \\
\hline
\end{tabular}

Educators reported almost equal levels of complete and partial ability to teach remotely, and few felt completely unable to do so. On the other hand, students and administrators reported low levels of complete ability to manage ERT, while $14 \%$ of students reported no ability at all.

The overall ability of all three stakeholder groups to implement ERT (Table 8), was mostly positive or partly so. However, given the gaps in confidence in using software and other tools (Tables 5 and 7) it is not surprising that ability was reported to be partially or wholly lacking in some cases.

\section{Reinforcement}

This section of the results focuses on the structures across the programmes included in this study that were found to reinforce or constrain the adoption and maintenance of ERT. Educator and student assessments are given in Table 9. 
Table 9

Educator and student assessment of resources available at home for successful ERT

\begin{tabular}{|lll|}
\hline Requirement & \multicolumn{2}{l|}{ \% positive responses } \\
\cline { 2 - 3 } & $\begin{array}{l}\text { Educators } \\
\mathbf{( N = 2 1 8}\end{array}$ & $\begin{array}{c}\text { Students } \\
\mathbf{( N = 1 0 6 1 )}\end{array}$ \\
\hline Reliable electricity at home & 81.7 & 60.4 \\
\hline Private space available to work at home & 75.2 & 53.4 \\
\hline Adequate time to do academic work at home & 79.4 & 56.2 \\
\hline Good connectivity at home & 70.2 & 39.0 \\
\hline A computer to use at home & 88.5 & 69.4 \\
\hline A smartphone to use at home & 85.3 & 88.6 \\
\hline $\begin{array}{l}\text { Teaching/ learning materials needed are available at } \\
\text { home }\end{array}$ & 67.9 & 46.1 \\
\hline Technical support available at home & 52.3 & \\
\hline
\end{tabular}

There were clear differences in educator and student assessment of the resources that would enable them to carry out ERT successfully in a home setting: educators reported having considerably more of these resources available.

For educators devices such as computers and smartphones were mostly available, as was reliable electricity. Most reported having adequate time and private space for their academic work; adequate connectivity and availability of teaching materials less so. In qualitative comments educators reported reliable internet access as a key factor in supporting the change to ERT - many had access either at work or at home, but this was variable; most could afford the data required. The support given by university structures (e.g., libraries) was noted and appreciated but only half reported that their ability to find technical support was adequate. The support and dedication of students and their families was noted as a key element of support for ERT.

Student perceptions of reinforcing and limiting factors were varied. Two highly valued reinforcing factors were conducive family dynamics and a quiet space in which to work undisturbed at home but only about half had this privilege. Internet access was a challenge for many, in terms of electricity supply, connectivity and cost:

"I have to walk quite a long distance to my uncle's house where there is better connectivity" (Student).

"Although I am privileged enough to have been able to attend online school, more than $75 \%$ of the class was not able to because of a lack of resources and connectivity. However, the teaching continued without them and that was unfair" (Student). 
Having appropriate devices was perceived as essential. Most reported having access to smartphones but noted their limited functionality; computer ownership and access were much more problematic:

"I use my phone to read and the words will be small" (Student).

"I have to share the laptop with my 3 siblings" (Student)

In qualitative comments students' ability to use relevant online platforms for ERT was noted to be a reinforcing factor, although lack of sufficient time to learn in the 'new normal' was mentioned as a constraint. Students appreciated online learning materials provided, for example recorded lectures and voiceover PowerPoints, as well as other forms of material and moral support from their programmes:

"Due to several challenges (electricity, data costs, and home environment) not all the students are able to take part in synchronous learning. Learning material is then sent on WhatsApp and Google Classroom and the students can interact with it when circumstances allow" (Educator).

In some cases, institutional support was perceived not to be sufficient at all, notably due to poor communication. Moral and practical support from families, community members and senior students was mentioned as a reinforcing factor for ERT, so that in some cases student attitudes were remarkably positive:

"All I want to be is the best. While others are complaining of the situation, I know I can spread my wings and fly high up their heads. I am competing at a global scale so whenever I study, I think of that other student in Europe who has everything at his disposal but still I want to make a better doctor than him" (Student).

Administrators' assessment of the institutional resources needed to sustain ERT successfully was largely negative (Table 10). 
Table 10

Administrators' assessment of institutional resources for ERT

\begin{tabular}{|ll|}
\hline Resource & \% positive responses (N=28) \\
\hline Institution's staffing level is sufficient to support ERT & 57.1 \\
\hline Instruction's budget sufficient to support ERT & 14.3 \\
\hline Institution is flexible enough to accept innovations needed for ERT & 53.6 \\
\hline Accrediting professional bodies will accept changes due to ERT & 60.7 \\
\hline Institution's bandwidth is sufficient to cope with ERT & 25.0 \\
\hline Institution's hardware is sufficient for ERT & 25.0 \\
\hline Institution's software is sufficient for ERT & 35.7 \\
\hline Institution's library services are geared for ERT & 35.7 \\
\hline Institution can provide psychosocial support to students during ERT & 35.7 \\
\hline
\end{tabular}

Budgets were particularly judged to be inadequate - so too the bandwidth and hardware needed. More than half of administrators assessed library service support, software availability, staffing levels and the psychosocial support available to students to be inadequate.

"Lack of serious support from the parent institution to provide preventive measures in the School....... Lack of moral support to staff who record cases of Covid 19 positive [sic].... and also lack of disclosing the results of students and or academic staff who test positive" (Administrator).

Assessment of institutional and professional body flexibility to accommodate ERT was somewhat more positive but still not high. On the other hand, administrators valued the skill, enthusiasm, and commitment of staff and students who pulled together to make the new learning system work.

\section{Discussion}

In this study, we set out to describe the change process through which selected HPEls in the Southern African region had adjusted their academic programmes to prepare for remote learning and teaching during the COVID-19 related pandemic. The synthesis and interpretation of the findings was done through the lens of the ADKAR model, which Prosci® describes as a relevant model for describing and informing change within organisations [20]. Overall, the institutions included in this study appear to have adjusted their nursing and medical programmes in response to the COVID-19 pandemic. These reported programmes and institutional adjustments influenced the structure and implementation of their educational programmes.

All the included institutions and programmes reported an awareness of the need to adopt ERT for learning and teaching during the COVID-19 pandemic. This awareness was brought about by the national 
responses to the COVID-19 pandemic, which restricted physical and social gatherings as well as limited infrastructure and policy for formal online learning [26]. Furthermore, all institutions were expected to continue learning and teaching during this time with online and electronic platforms (including social media) being a proximal emergency solution. Yusuf highlighted the need for continued education, especially for health professions, to supplement the health professionals at the coalface of the COVID-19 pandemic [27]. Positive awareness of the need for change is an essential initial aspect of the change process, creating opportunities for sustained change.

The desire to change is associated with a personal decision to change and engage with the ERT. The students, educators, and administrators in this study reported a strong desire to engage with the adoption of ERT as part of educational strategies during the COVID-19 pandemic. This desire may have been related to the abrupt implementation of containment measures and the drive for continued education. Prosci® explains that the desire to change is enhanced in the change process when the alternative of not implementing the change is worse, when the fear of penalty is high or when there is a desire to belong [20]. In this case, failing to complete an academic year would have had dire consequences for students, educators, and administrators. Students would not graduate in time, with implications such as financing, while educators might have increased workloads since they would have to cope with students with backlogs in addition to their normal programmes. The health delivery system, which is in dire need of health professionals, would suffer from a truncated production pipeline of health professionals. Whether this desire and the changes it engendered would result in long-term change is still open to question.

Stakeholders in this study appear to have fair but varying knowledge on how to adopt ERT and how to perform within the ERT-related platforms. Prosci ${ }^{\circledR}$, mentions that knowledge is only effective in adopting change when there is established awareness and desire related to the change [20]. In this study, most of the knowledge reported by the included stakeholders was based on prior experience of engaging with learning platforms outside an emergency teaching atmosphere. True to the definition of ERT there would not have been sufficient time for formal learning and training related to the implementation of ERT resources [28]. Some institutions, through their administrators, had instituted strategies aimed at supporting the knowledge of educators and students regarding ERT through training and education. Levett-Jones mentions that a well-established awareness and desire is fundamental in driving selfdirected learning approaches among individuals in developing their own knowledge [29]. This selfdirectedness may have been essential in developing the knowledge of educators who may not have had opportunities for formal institution-based education and training.

Interestingly educators and students were found to have similar knowledge and experience of software needed for learning, thus bucking the trend where students tend to be more skilled than their educators. However, many educators and students report being only partly skilled or not skilled at all. Ferri, Grifoni, and Guzzo attest that pedagogical challenges were embedded in their adaptation to remote teaching in Italy [30]. These pedagogical challenges referred to the lack of digital skills of some educators and students. Educators and students within Southern Africa need support on education-related software to enhance pedagogy within electronic platforms within the remits of their universities. Consequently, some 
institutions in the Southern African region appear to have a dedicated staff for such educator and student support; however, this is not the same across all institutions included in this study. Self-paced electronic platforms where educators and students can access and learn about learning and teaching software are essential in the African context.

Prosci ${ }^{\circledR}$ defines ability as the demonstration of the required changes, which in essence is the translation of knowledge into performance [20]. In this study, the ability of the included stakeholders was drawn from self-reported data and not the direct observation of performance. Evans et al. in their argument for feedback in education, explain the limitation of self-assessment, where self-assessment outcomes are usually not correlated to actual performance - where individuals often rate their performance higher than their actual performance: the so-called Dunning-Kruger effect [31,32]. Nevertheless, the participants in this study rated their abilities to apply ERT and learning within their own academic milieu highly, since there was limited institutional support. The literature explains that sufficient time, practice, access to the appropriate tools, including the presence of a coach or role model, are essential elements in fostering the ability to engage with change [20].

A generic challenge across many higher education institutions globally relates to adequate resources for learning and teaching influencing strategies towards the reinforcement of adoption of FOL. In this study, resources for learning and teaching were examined as potential strategies for reinforcing approaches for remote learning and teaching. A higher proportion of the educators claimed to have a constant electricity and internet supply while this was not the same for students. Devices for learning and teaching and adequate learning spaces were not optimally available for students, and institutions appear not to have sufficiently budgeted for this change. These findings are similar to those reported by Ferri, Grifoni, and Guzzo [30], where technological challenges appear to be a common challenge in implementing online teaching even in technologically advanced countries like Estonia. Even so the data clearly indicate that significant steps have been taken in these institutions towards integrating FOL more fully into their programmes.

\section{Recommendations}

Based on the findings of this study we argue for concerted efforts at the regional and institutional level that may enhance quality and equity of the educational experience of all health professions students.

In terms of practice, we recommend that institutions should arrange for remedial opportunities for those students that missed learning because of the lockdown. Educational institutions like those in Southern Africa should consider consolidating efforts in devising strategies to enhance remote learning and teaching. Such efforts could include improving learning and teaching infrastructure, zero-rating institutional websites, and providing limited amounts of free data for personal devices, and sharing learning materials across institutions. Institutions with advanced faculty development programmes may be essential in developing shareable programmes for the Southern African context. Co-constructivist 
approaches could also be embedded in learning and teaching, further allowing students to have a voice in how they are taught within the electronic space.

At the policy level, institutional strategic directives should prioritise continuing professional development for educators as well as strengthening development and investment in educational infrastructure which supports online learning and teaching. Exemplary educational practice should be recognised and rewarded.

In terms of research, there is need to evaluate further the ability to implement ERT by educators, students, and administrators within this setting. In addition, research should be undertaken which focuses on evaluating the impact of remote learning and teaching on health professions education students in the Southern African region. Outcomes from such research may be useful in the design and implementation of purposive induction or mentorship programmes for graduates who may not essentially be competent or workplace ready.

\section{Study limitations}

The response rate across all institutions included in this study was low - during the COVID-19 pandemic there were many other studies inviting participation. This could have overwhelmed the sample population leading to a poor response rate. As a result, this study's results are not intended for generalization across the continent or programmes. Similarly, the original intention was to include case studies from fifteen programmes in eight participating institutions, but this proved not to be possible due to challenges faced with data collection and reporting within the timeframes agreed upon by the research team. The results presented in this collective case study therefore exclude findings from four programmes.

\section{Conclusion}

HPEls in the Southern African region have attempted to adjust their educational programmes in response to COVID-19. These adjustments were affected by limited resources, limited educator competencies, and students' challenging home environments. Inasmuch as the need to complete the academic year appears to be a proximal justification for the adoption of ERT the impact of the quality of such approaches on the integrity of training of healthcare graduates from these institutions needs further investigation. Educational institutions should ensure that competence is not compromised in an already poorly resourced and heavily burdened health delivery system in Southern Africa.

We are of the opinion that valuable information expressed in this study, including the conclusions that we drew, may well resonate with many institutions and individuals in the continent and that recommendations from this study may be of use.

\section{List Of Abbreviations}

ADKAR - Aware, Desire, Knowledge, Ability, Reinforce Framework 
COVID-19 - Coronavirus Disease 19

ERT - Emergency Remote Teaching

FOL - Full Online Learning

HPEI - Health Professions Education Institution

ICT - Information, Communication and Technology

IRB - Institutional Review Board

WHO - World Health Organization

\section{Declarations}

\section{Ethics approval and consent to participate}

Relevant safeguards required during research involving human research participants, as outlined in the Belmont Report of 1979 and the International Conference on Harmonization (ICH) of 2002, were applied as the overarching ethics framework for this study. IRB approval was obtained at various times across the participating sites, which were free to commence data collection as soon as local IRB was obtained (Table 1). Data collection began on October 1st, 2020 and ended on March 31 ${ }^{\text {st }}, 2021$.

\section{Consent for publication}

Not applicable

\section{Availability of data and materials}

The datasets used and/or analysed during the current study are available from the corresponding author on reasonable request.

\section{Competing interests}

The authors declare that they have no competing interests.

\section{Funding}

The study has not received any funding. Any costs involved were borne by individual consortium members at the various institutions.

\section{Authors' contributions}

SC was the principal investigator who conceived the idea and formed the team, led the research process, and maintained team cohesion. CN and DP were co-principal investigators who participated in shaping 
the idea and conduct of the research process. $\mathrm{CN}$ developed and coordinated the electronic versions of the data capture tools. DP provided scholarly insights and guidance on the case study approach. SC, CN, MNK, QW, IN and DP were members of a core team responsible for writing and refining the manuscript. EK, RG, GK, PKM, RM, RN, LP, KD, CM, AGM, SNM and LvdM participated in the research, and writing and approval of the final manuscript.

\section{Acknowledgements}

We acknowledge statistical support from Professor Gina Joubert and technical support from Dr Bennie Botha from the University of the Free State, South Africa. The authors acknowledge the expert opinion from Prof Werner Cordier who critically read this paper and Ms Delena Sturwig for language editing.

\section{References}

1. World Health Organization. COVID 19 Public Health Emergency of International Concern (PHEIC). Global research and innovation forum: towards a research roadmap. 2020;

2. World Health Organization. Novel Coronavirus ( 2019-nCoV): situation report, 11. World Health Organization; 2020;

3. World Economic Forum. What will higher education in Africa look like after COVID-19?. Available from: https://www.weforum.org/agenda/2020/06/higher-education-africa-covid19-coronavirusdigital-online/

4. Schmutz AM, Jenkins LS, Coetzee F, Conradie H, Irlam J, Joubert EM, et al. Re-imagining health professions education in the coronavirus disease 2019 era: Perspectives from South Africa. African Journal of Primary Health Care \& Family Medicine. 2021;13:5.

5. Greysen SR, Dovlo D, Olapade-Olaopa EO, Jacobs M, Sewankambo N, Mullan F. Medical education in sub-Saharan Africa: a literature review. Medical education. Wiley Online Library; 2011;45:973-86.

6. AlHaqwi Al, Kuntze J, van der Molen HT. Development of the clinical learning evaluation questionnaire for undergraduate clinical education: factor structure, validity, and reliability study. BMC Medical Education. BioMed Central; 2014;14:1-8.

7. Liljedahl M, Björck E, Kalén S, Ponzer S, Laksov KB. To belong or not to belong: nursing students' interactions with clinical learning environments-an observational study. BMC medical education. BioMed Central; 2016;16:1-10.

8. Ossai EN, Ogbuoji O. Redressing the impact of COVID-19 on medical education in Africa: the need for collective action. BMJ global health. BMJ Specialist Journals; 2021;6:e005067.

9. Hodgson JC, Hagan P. Medical education adaptations during a pandemic: Transitioning to virtual student support. Medical Education. 2020;54:662-3.

10. Khalil R, Mansour AE, Fadda WA, Almisnid K, Aldamegh M, Al-Nafeesah A, et al. The sudden transition to synchronized online learning during the COVID-19 pandemic in Saudi Arabia: a 
qualitative study exploring medical students' perspectives. BMC medical education. Springer; 2020;20:1-10.

11. World Health Organization. Transforming and scaling up health professionals' education and training: World Health Organization guidelines 2013. [Internet]. 2013 [cited 2020 Jun 23]. Available from: http://www.ncbi.nlm.nih.gov/books/NBK298953/

12. Kagawa MN, Chipamaunga S, Prozesky D, Kafumukache E, Gwini R, Kandawasvika G, et al. Assessment of Preparedness for Remote Teaching and Learning to Transform Health Professions Education in Sub-Saharan Africa in Response to the COVID-19 Pandemic: Protocol for a Mixed Methods Study With a Case Study Approach. JMIR research protocols. JMIR Publications Inc., Toronto, Canada; 2021;10:e28905.

13. Gordon M, Patricio M, Horne L, Muston A, Alston SR, Pammi M, et al. Developments in medical education in response to the COVID-19 pandemic: A rapid BEME systematic review: BEME Guide No. 63. Medical Teacher. Taylor \& Francis; 2020;42:1202-15.

14. Oliveira G, Grenha Teixeira J, Torres A, Morais C. An exploratory study on the emergency remote education experience of higher education students and teachers during the COVID-19 pandemic. British Journal of Educational Technology. Wiley Online Library; 2021;

15. Mukhtar K, Javed K, Arooj M, Sethi A. Advantages, Limitations and Recommendations for online learning during COVID-19 pandemic era. Pakistan journal of medical sciences. Professional Medical Publications; 2020;36:S27.

16. Kaliisa R, Picard M. A systematic review on mobile learning in higher education: The African perspective. Turkish Online Journal of Educational Technology-TOJET. ERIC; 2017;16:1-18.

17. Mshana JA. Effectiveness of Mobile Learning as a means of Distance Learning in Tanzania. Huria: Journal of the Open University of Tanzania. Open University of Tanzania, 2018; 2018;25:209-32.

18. Kachian A, Elyasi S, Haghani H. ADKAR Model and Nurses' Readiness for Change. Journal of ClientCentered Nursing Care. Journal of Client-Centered Nursing Care; 2018;4:203-12.

19. Hiatt J. ADKAR: a model for change in business, government, and our community. Prosci; 2006.

20. The Prosci ADKAR® Model | Prosci [Internet]. [cited 2021 Jun 28]. Available from: https://www.prosci.com/methodology/adkar

21. Yin RK. Case study research: Design and Methods. Sage; 2009.

22. Etikan I, Musa SA, Alkassim RS. Comparison of convenience sampling and purposive sampling. American journal of theoretical and applied statistics. New York; 2016;5:1-4.

23. Biomedical USNC for the P of HS of, Research B. The Belmont report: ethical principles and guidelines for the protection of human subjects of research. The Commission; 1978.

24. Dixon JR. The international conference on harmonization good clinical practice guideline. Quality Assurance. Taylor \& Francis; 1999;6:65-74.

25. Mulenga LB, Hines JZ, Fwoloshi S, Chirwa L, Siwingwa M, Yingst S, et al. Prevalence of SARS-CoV-2 in six districts in Zambia in July, 2020: a cross-sectional cluster sample survey. The Lancet Global 
Health. Elsevier; 2021;9:e773-81.

26. Ifijeh G, Yusuf F. Covid-19 pandemic and the future of Nigeria's university system: The quest for libraries' relevance. The Journal of Academic Librarianship. Elsevier; 2020;46:102226.

27. Schlesselman LS. Perspective from a teaching and learning center during emergency remote teaching. American journal of pharmaceutical education. American Journal of Pharmaceutical Education; 2020;84.

28. Levett-Jones TL. Self-directed learning: Implications and limitations for undergraduate nursing education. Nurse Education Today. Elsevier; 2005;25:363-8.

29. Ferri F, Grifoni P, Guzzo T. Online learning and emergency remote teaching: Opportunities and challenges in emergency situations. Societies. Multidisciplinary Digital Publishing Institute; 2020;10:86.

30. Evans AW, Mckenna C, Oliver M. Self-assessment in medical practice. Journal of the Royal Society of Medicine. SAGE Publications Sage UK: London, England; 2002;95:511-3.

31. Kruger J, Dunning D. Unskilled and unaware of it: how difficulties in recognizing one's own incompetence lead to inflated self-assessments. Journal of personality and social psychology. American Psychological Association; 1999;77:1121.

\section{Figures}

\section{Image not available with this version}

\section{Figure 1}

In this study we used the ADKAR framework [18-20] to formulate the research questions, and analyse and interpret data (Fig. 1). 